OPEN ACCESS

Edited by:

Massimo Antonio Padalino,

University of Padua, Italy

Reviewed by:

Gidon Yehuda Perlman,

Hadassah Medical Center, Israel

Biagio Castaldi

University of Padua, Italy

${ }^{*}$ Correspondence:

Pierre Aubry

pcaubry@yahoo.fr

Specialty section:

This article was submitted to Structural Interventional Cardiology, a section of the journal

Frontiers in Cardiovascular Medicine

Received: 18 August 2020

Accepted: 18 December 2020

Published: 18 January 2021

Citation:

Aubry P, Halna du Fretay $X$

Boudvillain O, Degrell $P$ and the ANOCOR Working Group (2021) Place

of Angioplasty for Coronary Artery

Anomalies With Interarterial Course. Front. Cardiovasc. Med. 7:596018

doi: 10.3389/fcvm.2020.596018

\section{Place of Angioplasty for Coronary Artery Anomalies With Interarterial Course}

\author{
Pierre Aubry ${ }^{1,2 *}$, Xavier Halna du Fretay ${ }^{3}$, Olivier Boudvillain ${ }^{1}$, Philippe Degrell ${ }^{4}$ and \\ the ANOCOR Working Group
}

${ }^{1}$ Bichat Hospital, Department of Cardiology, Paris, France, ${ }^{2}$ entre Hospitalier de Gonesse, Department of Cardiology, Gonesse, France, ${ }^{3}$ Pôle Santé Oréliance, Department of Cardiology, Saran, France, ${ }^{4}$ Centre Hospitalier du Luxembourg, Institut National de Chirurgie Cardiaque et de Cardiologie Interventionnelle, Luxembourg, Luxembourg

Few patients with an anomalous aortic origin of a coronary artery (AAOCA) require a correction of this congenital anomaly. Current recommendations offer surgical repair as a first line therapy to prevent a sudden cardiac death as a main objective. However, these guidelines are focused on children and not based on randomized controlled studies. Furthermore, decision-making should be different in an adult population less exposed to the risk of sudden cardiac death. Current practices showed reluctance to offer a surgical treatment for right AAOCA associated with ischemic symptoms or myocardial ischemia. Our aim in this review is to expose the rationale for percutaneous coronary intervention in right AAOCA with interarterial course and to present the published results.

Keywords: congenital coronary anomaly, anomalous aortic origin, interarterial course, angioplasty, stenting

\section{INTRODUCTION}

Diagnosis of an anomalous aortic origin of a coronary artery (AAOCA) is not rare in the adult population. A prevalence of $0.8 \%$ has been reported with coronary computed tomography angiography (CCTA) (1). Only a part of AAOCA (roughly one-third, i.e., anomalies with an interarterial course between the great vessels) may be associated with cardiovascular events or symptoms (2). The first presentation of these anomalies, so-called AAOCA at risk, is variable, ranging from an incident finding to ischemic symptoms or sudden cardiac death (SCD). The latter is rarely the first event in adults $>35$ years of age (3). Functional tests are often not able to demonstrate inducible ischemia, even in symptomatic patients (4). When an AAOCA correction is offered, surgical intervention is recommended in current guidelines. But the latter are generally focused on young people $(5,6)$. The optimal management strategy for older patients with AAOCA at risk remains debated given uncertainties related to the individual risk of SCD or aborted sudden cardiac arrest (SCA), corrected-and not corrected AAOCA natural history, and the risks and failures of the surgery (7). Multidisciplinary teams in charge of AAOCA in the adult population are sometimes faced with a difficult therapeutic choice between a conservative strategy and surgery (8). This review aims to present the possibilities offered by percutaneous coronary intervention (PCI) which may be a realistic alternative to surgery. The PCI management of AAOCA associated with a significant coronary artery disease $(\mathrm{CAD})$ will not be addressed in this review. This work describes the experience and point of view of a French team dedicated to the ANOmalous CORonary arteries: the ANOCOR Working Group. 


\section{RATIONALE FOR TREATMENT}

Several points can be highlighted to understand the rationale for a treatment in the management strategy of AAOCA.

\section{Sudden Cardiac Death}

The relationship between AAOCA and SCD has been established a long time ago (9-12). The risk of SCD leads to anxiety for patients with AAOCA identified at risk, and numerous interrogations for referring practitioners. Post-mortem studies showed that AAOCA is one of the most frequent causes of SCD in athletes $(13,14)$. Unfortunately, we have no tools to stratify the individual risk of SCD in patients with AAOCA. While the absolute risk is only based on estimations (annual risk of 0.2 and $0.02 \%$ for left and right coronary artery, respectively), this risk is particularly low in comparison to the risk of other congenital cardiac diseases identified at-risk of SCD (i.e., hypertrophic cardiomyopathy, arrhythmogenic right ventricular dysplasia, or electric syndromes) $(7,15,16)$. The pathophysiological mechanisms that lead to SCD are not fully understood. Physical effort induced-myocardial ischemia is only one of the factors leading to a fatal ventricular arrhythmia. Age $<30$ years, intense exercise activities, syncope on exertion, left (L)-AAOCA with interarterial course, and maybe myocardial fibrosis scars, are recognized as risk factors for $\operatorname{SCD}(3,4,16,17)$. Unfortunately the majority of L-AAOCA at risk is diagnosed postmortem (18). SCD has been described over 35 years of age, but seems particularly rare, especially in patients with right (R)AAOCA (3). Therefore, the question of primary prevention of SCD should not be asked in the same way for, on the one hand, a young population with L-AAOCA, and on the other hand, older patients with R-AAOCA. After an aborted SCA, a surgical correction is recommended (19), and an internal cardioverter defibrillator is sometimes discussed.

\section{Ischemic Symptoms and Myocardial Ischemia}

A vast majority of AAOCA at risk may remain asymptomatic for a long time, ischemic symptoms, that may mimic a CAD, are possible. AAOCA diagnosis is made by invasive coronary angiography (ICA) or CCTA. Given the difficulty to demonstrate myocardial ischemia by functional non-invasive tests in AAOCA, it seems acceptable to consider non-equivocal symptoms (angina, dyspnea, and syncope, especially on exertion) as ischemic symptoms, even if documented myocardial ischemia is lacking. Symptoms highly suggestive of ischemia are generally included in algorithms for the management of AAOCA $(5,6,20,21)$. Silent myocardial ischemia and severe ventricular arrhythmias must be taken into account in the same way. Considering our knowledge and current guidelines on CAD, medical treatment, PCI, or surgery could be discussed for a symptomatic patient

Abbreviations: AAOCA, anomalous aortic origin of a coronary artery; AATS, American Association for Thoracic Surgeons; ANOCOR, ANOmalous CORonary arteries; CAD, coronary artery disease; CCTA, coronary computed tomography angiography; ICA, invasive coronary artery; IVUS, intravascular ultrasound; FFR, fractional flow reserve; PCI, percutaneous coronary intervention; SCA, sudden cardiac arrest; SCD, sudden cardiac death. with AAOCA, with the main goals of functional improvement and cardiac events prevention. No controlled randomized study to date has compared the use of anti-ischemic drugs to an alternative strategy in the field of AAOCA. If a SCD may be the first cardiac event, prior ischemic symptoms can be found in nearly half of the cases by questioning the bystanders, entourage or the patient himself in case of aborted SCA (15). Therefore, a correction should always be discussed in AAOCA with ischemic symptoms or documented myocardial ischemia, regardless of age.

\section{Current Recommendations}

Surgery is recommended as first line therapy in current guidelines for symptomatic AAOCA with interarterial course. In the expert consensus guidelines from the American Association for Thoracic Surgeons (AATS), the authors give a Class 1/Level B indication for any patient with a L-AAOCA at risk, with or without symptoms, or with a symptomatic R-AAOCA at risk (5). In the $2018 \mathrm{AHA} / \mathrm{ACC}$ guidelines for the management of adults with congenital heart disease, surgery is recommended (Class 1, Level B-NR) for AAOCA at risk with ischemic symptoms or myocardial ischemia, and is reasonable (Class IIa/Level CLD) for L-AAOCA at risk without ischemic symptoms or documented myocardial ischemia (6). Surgery or continued observation may be reasonable (Class IIb/Level B-NR) in asymptomatic R-AAOCA without inducible myocardial ischemia or anatomic severity criteria. AATS guidelines don't offer surgery in R-AAOCA without ischemic symptoms or myocardial ischemia. The recent European Guidelines are very close to the Nord American recommendations (21). While the risk of SCD depends strongly on age, the latter is not always taken into account in the current guidelines. To date, none of these recommendations is based on randomized controlled studies. Some authors have pointed out that we don't have objective evidence to strongly recommend surgery in all circumstances. The place of PCI is only addressed in AATS guidelines (5), for adults with high risk for surgery (Class IIb/Level C).

\section{Strengths and Weaknesses of Surgery}

Several surgical techniques have been developed in the field of AAOCA. Because of the risk of competitive flow, coronary artery bypass grafting is not recommended unless it is associated to a proximal coronary ligation, or in patients with significant $\mathrm{CAD}$ beyond the interarterial course. A more anatomic approach is to create a neo-orifice in the appropriate sinus, either by an unroofing procedure with ablation of the intramural aortic segment, or by ostioplasty with patch enlargement (22). A direct reimplantation technique is generally not suitable. Surgical anatomic repair permits to bypass an interarterial course associated or not with an intramural segment. Nevertheless, these therapies carry some risks, and the net benefit against the risk of SCD has not yet been clearly proved. The perioperative mortality is remarkably low at almost zero, with a mild morbidity related to complications of sternotomy and extracorporeal circulation $(23,24)$. Other complications in relation with surgical technique have been described. Aortic insufficiency by injury of the intercoronary commissure is the main complication 
observed after an unroofing procedure $(25,26)$. Early and late complications have also been described with ostioplasty, such as acute occlusion, scarring stenosis, or pseudo-aneurysm (26). The risk of SCD or myocardial ischemia must be heightened against the risk of surgery and the risk of potential late complications. Rarely, aborted SCA has been reported after surgical repair of AAOCA (26).

\section{ANATOMICAL AND PHYSICAL CONSIDERATIONS}

The nature of coronary narrowings related to atherosclerosis or congenital disease differs greatly.

\section{Coronary and Aortic Anatomic Considerations}

It is admitted that a slit-like orifice is associated with an intramural aortic pathway. However, all AAOCA with interarterial course are not associated with the latter $(27,28)$. An intramural pathway implies a direct contact between the coronary media and aortic media. Coronary lumen deformation observed in AAOCA with interarterial course should be interpreted as an adaptation of angiogenesis to the limited space between the great vessels, and not as an extrinsic compression. An eccentric deformation with reduction of the lumen area is generally present in AAOAC with an interarterial course (29). Association of an acute connection angle $<30^{\circ}$ with a ratio $>1.5$ between long axis and short axis at the narrowest point refers to the presence of an intramural coronary segment embedded within the media of the aorta. The degree of surface reduction varies between 30 and $80 \%$. The length of the interarterial course segment, generally $>20 \mathrm{~mm}$, may vary depending of the site of the ectopic orifice. Without intravascular ultrasound (IVUS) guidance, the measurement of the intramural segment length is difficult.

\section{Coronary Physical Considerations}

Vascular lumen hypoplasia observed on any interarterial segment could be at least partially corrected by stenting. Our experience in CAD related-PCI showed that a lumen oversizing is possible by stenting of coronary arteries whose wall thickness is $<0.5 \mathrm{~mm}$. The intramural aortic pathway is associated with specific anatomic features, such as an ellipsoid section and a particularly thick wall (at least $1.0 \mathrm{~mm}$ with two media layers) due to the coronary wall embedded into the aortic wall. As a result, the required forces should be greater to optimize the remodeling of an ellipsoid section with an important increase in the minimal diameter and a small decrease in the maximal diameter. A postPCI circular shape is probably not an achievable target in case of intramural pathways. Due to the non-circular initial shape, mal-apposition of some struts at the edges may be possible. Risks of elastic recoil remain unknown after stenting of a thick arterial wall free of atherosclerosis. Given the proximity of the great vessels, distortion and/or fracture of metallic stents may be a cause of PCI failure with restenosis after several years of dynamic changes. Early in-stent restenosis by intimal hyperplasia remains possible. Aortic wall dissection during catheterization and balloon inflations can be an additional potential risk of the procedure.

\section{Mechanical Properties of Stents}

Uncertainties exist regarding the optimal result of AAOCA stenting. Stents are metallic structures that oppose compressive arterial forces. The mechanical characteristics of stents have not yet been studied in AAOCA. The concept of stenting was developed to improve the results of a balloon dilatation, with a better compression of the atherosclerotic burden and a lesser vascular elastic recoil. Coronary segments with an interarterial course are generally free of atherosclerosis. Basically, the aim of stenting in AAOCA will be performing a vascular remodeling.

\section{GOALS OF PCI}

There are anatomic and clinical objectives. Structural rigidity of stents may allow them to correct some anatomic features. Ostioplasty of a slit-like orifice and widening of an arterial segment hypoplasia are the expected effects of coronary stenting in this setting. In addition, metallic stents could prevent the presumed interarterial compression and dynamic changes of the intramural lumen morphology during intensive exercise. Clinical objectives are similar to those of the surgery, but in a different manner. The control of ischemic symptoms and the correction of induced myocardial ischemia should be the main objectives of PCI for the target population to be described further. The prevention of major cardiac events such as SCD is of course also expected.

\section{PCI PLANNING}

The next part of this review will be focused on the management of R-AAOCA. Indeed, the vast majority of adults for whom a correction is discussed, has R-AAOCA. Moreover, our current knowledge in the field of AAOCA should encourage us to keep surgery as a first line therapy for L-AAOCA, except for adults with high surgical risk.

\section{Indication of $\mathrm{PCl}$}

The evaluation and management of patients with AAOCA at risk should be best discussed by a dedicated multidisciplinary team (cardiologists, radiologists, and surgeons with experience in the AAOCA field). A standardized algorithm, regularly revised, should allow an optimal decision-making for each patient according to the initial presentation and diagnostic work-up. Patients aged over 30 years with R-AAOCA associated with ischemic symptoms and/or documented myocardial ischemia represent the potential population eligible for PCI.

\section{Non-invasive Imaging Evaluation}

Adequate imaging is essential to define anatomic characteristics. Currently CCTA is considered as the best tool to delineate accurately the ostium shape and initial morphology of AAOCA in the adult population $(1,30,31)$. A standardized interpretation is recommended including ostial morphology, take-off angle, 


\section{French Working Group for Anomalous Coronary Arteries}

\section{Standardized algorithm for patients with anomalous aortic origin of a coronary artery (AAOCA)}

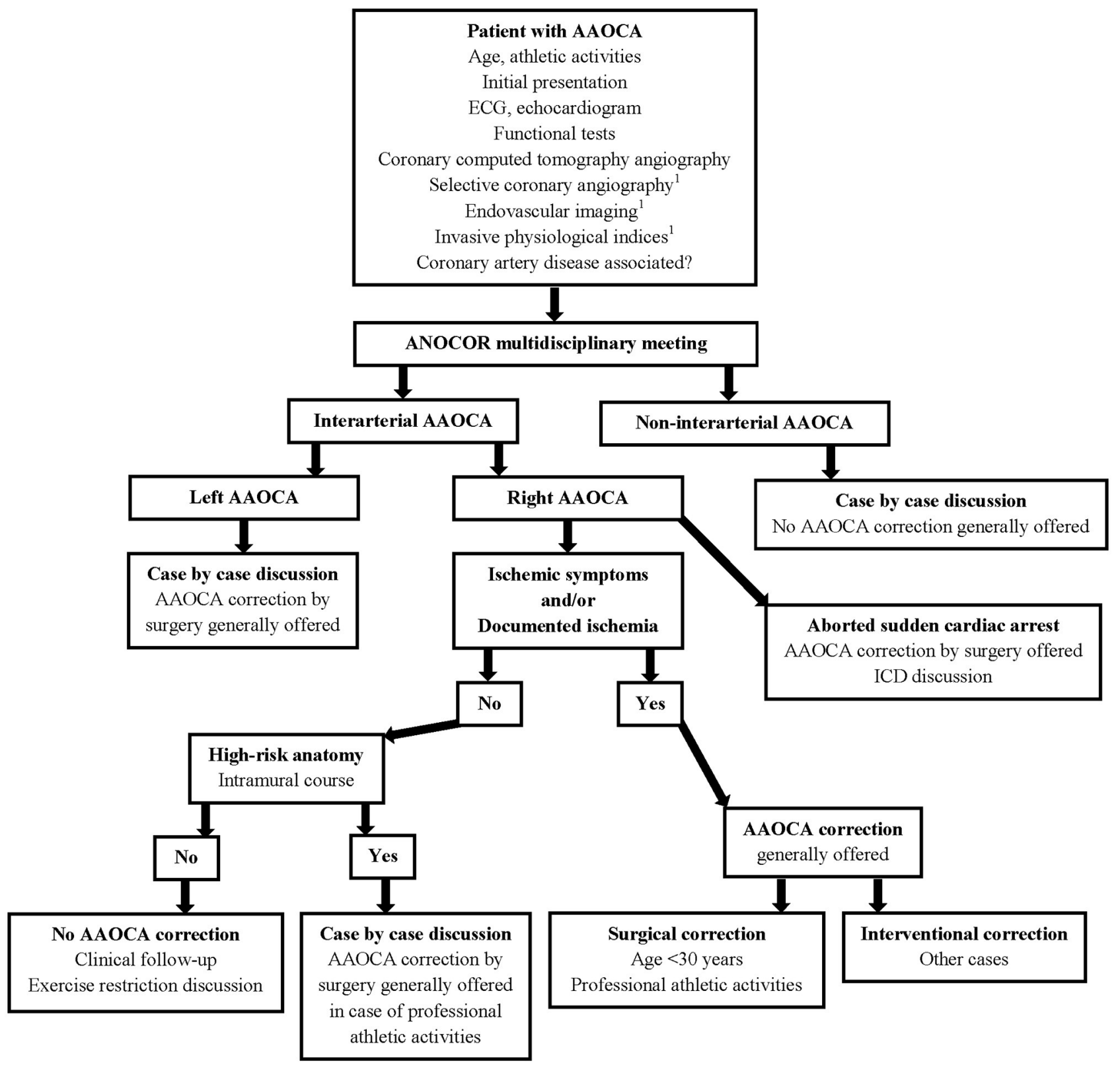

FIGURE 1 | Algorithm to evaluate and manage patients with anomalous aortic origin of a coronary artery (AAOCA). ${ }^{1}$ Optional.

degree of proximal narrowing compared to the distal part, degree of proximal lumen eccentricity defined as height/width ratio, presence and length of an intramural pathway, and length of the interarterial course. An interarterial course is easy to recognize by CCTA, but the assertion of an intramural pathway can be difficult. 


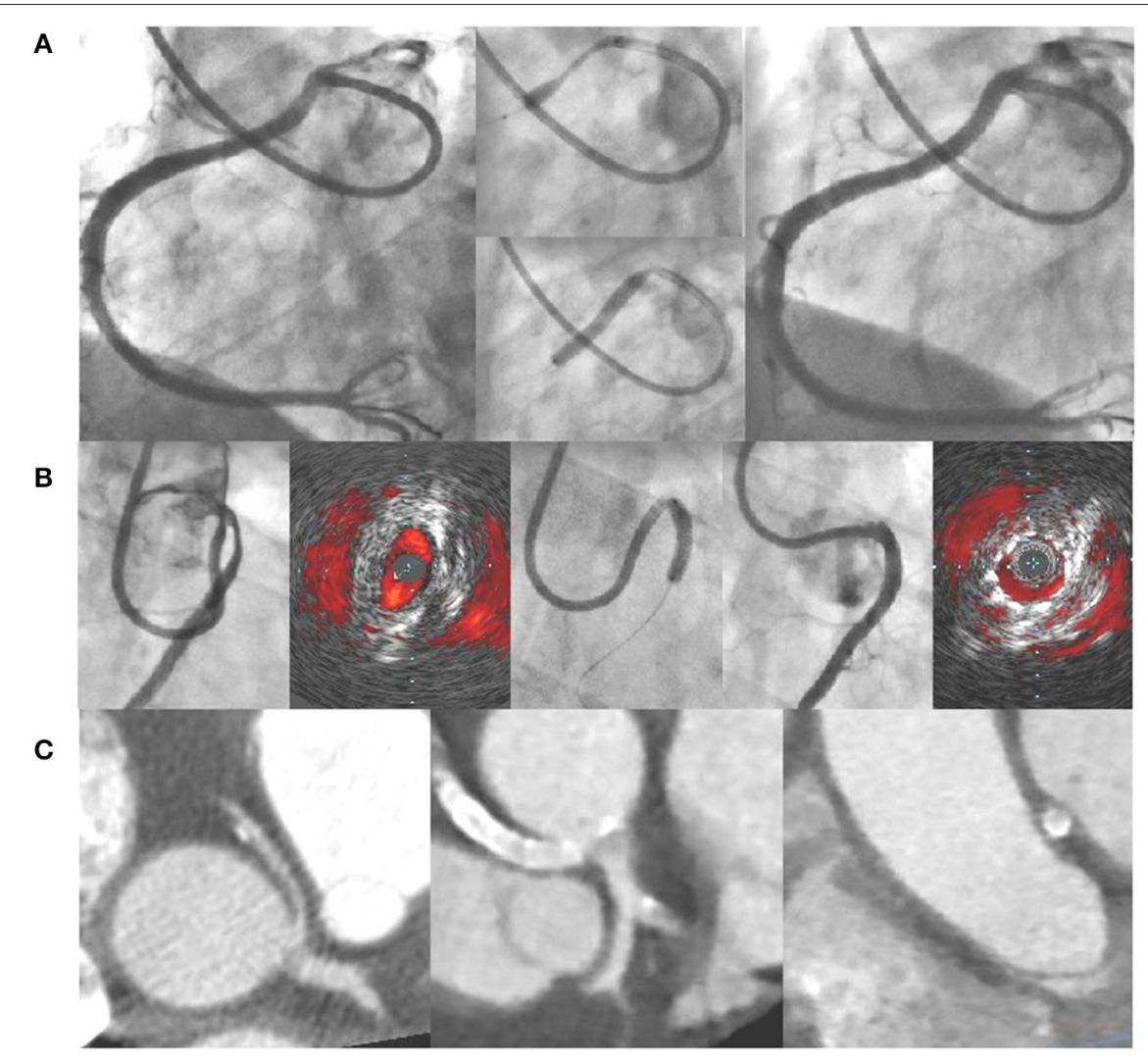

FIGURE 2 | (A) Example of angioplasty with stenting of a right AAOCA (pre-PCl, stent deployment, post-PCl); (B) angioplasty with stenting under IVUS guidance of a right AAOCA associated with an intramural pathway (pre-PCI, stent deployment, post-PCI); (C) CCTA images of a right AAOCA treated by angioplasty with stenting (pre- $\mathrm{PCl}$ and post-PCl at-6 month). AAOCA, anomalous aortic origin of a coronary artery; CCTA, coronary computed tomography angiography; PCl, percutaneous coronary intervention; IVUS, intravascular ultrasound.

TABLE 1 | Main characteristics of patients included in series of AAOCA treated by angioplasty with stenting.

\begin{tabular}{|c|c|c|c|c|c|c|c|c|}
\hline References & $\begin{array}{l}\text { AAOCA type } \\
\text { and number }\end{array}$ & $\begin{array}{c}\text { Mean age } \\
\text { years }\end{array}$ & $\begin{array}{c}\text { BMS/DES } \\
\text { number }\end{array}$ & $\begin{array}{l}\text { Angiographic } \\
\text { success (\%) }\end{array}$ & $\begin{array}{c}\text { Mean } \\
\text { follow-up } \\
\text { years }\end{array}$ & $\begin{array}{c}\text { In-stent } \\
\text { restenosis } \\
\text { number (\%) }\end{array}$ & $\begin{array}{c}\text { Stent } \\
\text { compression } \\
\text { number }(\%)\end{array}$ & $\begin{array}{c}\text { Sudden } \\
\text { cardiac } \\
\text { death } \\
\text { number }\end{array}$ \\
\hline Doorey et al. (33) & 3 Left/9 Right & 56 & $12 / 0$ & 100 & 0.5 & $3(25)$ & $1(8)$ & 0 \\
\hline Angelini et al. (35) & 42 Right & 48 & $3 / 39$ & 100 & 5.0 & $4(10)$ & 0 & 0 \\
\hline Degrell et al. (39) & 17 Right & 51 & $1 / 16$ & 100 & 2.0 & $2(12)$ & 0 & 0 \\
\hline
\end{tabular}

AAOCA, anomalous aortic origin of a coronary artery; BMS, bare metal stent; DES, drug eluting stent.

\section{Techniques of Catheterization}

Technical difficulties with catheters are often experienced with R-AAOCA. Given that the initial course is tangential to the aortic wall, canulation and coaxiality, with adequate back-up support, are frequently challenging. A slit-like orifice does not allow a selective canulation. Amplatz left (AL) type catheters are generally the first choice, but Extra-Back-Up (EBU) type catheters can be used. Subselectively advancing of a coronary guide-wire permits enhanced support and higher quality angiographies.

\section{Invasive Imaging and Physiological Evaluation}

Accurate morphological evaluation of AAOCA at risk is crucial. In the $2018 \mathrm{AHA} / \mathrm{ACC}$ guideline (6), coronary angiography using catheterization for anatomical and physiological evaluation is recommended in the adult population with AAOCA at risk (Class I, Level C-LD). To date, intravascular ultrasound (IVUS) appears as the imaging technique which provides the best qualitative and quantitative evaluation of the anatomy of AAOCA with an interarterial course (29). IVUS imaging visualizes the aortic 
wall at the level of an intramural pathway. The ostial shape and coronary narrowing are easily identified by IVUS with a manual pull-back method. Optical Coherence Tomography (OCT) can be used, but an adequate visualization of the orifice shape can be difficult. Physiological evaluation with pressure flow wires could be interesting. However, the Fractional Flow Reserve (FFR) measurement presents some pitfalls in AAOCA. The lack of selective injection needs a hyperemia induced by intravenous adenosine. In addition, the FFR cut-off for AAOCA is unknown. In a series of $25 \mathrm{R}$-AAOCA (32), a FFR value $\leq 0.80$ was observed in five of the cases (20\%). Rest indices such as iFR (instantaneous wave-Free Ratio) remain to be evaluated. So far, we don't have sufficient data to offer a FFR-guided treatment strategy in patients with AAOCA. Nevertheless, a physiological evaluation can be undergone when the decision making is difficult.

\section{Techniques of Angioplasty}

Remodeling of the lumen appears to be the main objective of PCI. Direct stenting is recommended. However, some operators proposed a pre angioplasty with a cutting-balloon. Empirically, drug-eluting stents with thicker struts and implanted with high pressures ( $\geq 20$ bars) should be used. The choice of the stent size should be at least the diameter of the coronary segment just downstream of the ectopic course. The stent should be deployed along the entire ectopic course, avoiding too much protrusion into the aorta. PCI guidance by IVUS is recommended for the evaluation of the ectopic segment (diameters, area, and length) and for the control after stenting.

\section{RESULTS OF PCI}

\section{Published Data}

The published literature of PCI for AAOCA with an interarterial course remains limited (33-36). Specific treatments of interarterial segment narrowings by PCI should not be confused with percutaneous interventions planned for atherosclerotic stenosis on distal segments of AAOCA with an interarterial course. Several intravascular ultrasound series suggest that the interarterial course of AAOCA is usually free of atherosclerotic disease $(32,37,38)$. Doorey et al. reported in 2000 the first experience of PCI for AAOCA with an interarterial course in 12 patients with a mean age of 55 years [44-70] (33). All patients (3 L-AAOCA and 9 R-AAOCA) had abnormal nuclear perfusion imaging tests before stenting. Angiographic success with bare metal stents was obtained in all patients without complications. All patients had normal myocardial functional tests at 6-month follow-up. Angelini et al. have reported in 2015 the largest series with 42 patients with right AAOCA, who underwent PCI because of significant symptoms, positive stress tests, and/or significant stenosis (35). Interestingly, 5 patients had had previous coronary artery bypass grafting to treat RAAOCA (4 non-functional internal mammary artery grafts and one occluded venous graft). The stenting procedure performed under IVUS guidance was successful in all patients without complications. Drug-eluting stents were used in a majority of cases (39/42). The cross-sectional area increased after stenting from 4.8 to $10.8 \mathrm{~mm}^{2}$, reducing the stenosis area from 58 to $8 \%$. Twenty-three (55\%) patients underwent follow-up test stressing by nuclear perfusion imaging; only two had perfusion defects in the stented areas. During follow-up (mean $5.0 \pm 2.9$ years; range 1.1-12.1 years) a significant in-stent restenosis was diagnosed in $4(10 \%)$ patients; two of them had bare metal stents. Three patients underwent in-stent balloon angioplasty and one patient underwent surgery with a mammary artery graft at 6 years for iterative restenosis. Darki et al. reported recently a short series of 4 R-AAOCA treated with drug-eluting stents (36). All patients were symptomatic at presentation. Angiographic success was achieved in all of the cases. All patients were symptom-free after PCI. On the follow-up CCTA (mean duration of 1.4 years), no evidence of stent distortion or fracture was observed. Furthermore, PCI can be used to treat some surgery failures, such as acute occlusion or scarring stenosis (26).

\section{ANOCOR Working Group Experience}

Based on this experience reported in the literature, the ANOCOR Working Group has started since 2014 a prospective registry (ANOCOR Stenting) of patients with R-AAOCA and treated by PCI with stenting (39). All patients were discussed in monthly multidisciplinary meetings. A decisionmaking algorithm (Figure 1) was applied for the evaluation and management of patients with AAOCA. Aborted SCA was considered an exclusion criteria. A percutaneous treatment by stenting was proposed for patients with R-AAOCA referred to the expert group according to predefined criteria: age $>30$ years (except for patients with a left coronary dominance), ischemic symptoms or documented myocardial ischemia, interarterial course). All patients underwent invasive CA and CCTA. Additional evaluation by IVUS or OCT was recommended. Clinical follow-up was scheduled at 6, 12, and 60 months by phone contact. Systematic CCTA and functional testing with imaging were proposed between 6 and 12 months. Patients continued dual antiplatelet therapy for at least 6 months. Seventeen patients (mean age 51 years) were prospectively included between 2014 and 2019. Two patients had acute coronary syndrome, twelve had stable angina, two were asymptomatic with a positive stress test and one had syncope. An intramural segment was identified in more than half of the patients. Stenting was successful with residual angiographic stenosis $<30 \%$ in all of the procedures, $47 \%$ radial access, $94 \%$ of drug-eluting stents, mean stent diameter $3.5 \mathrm{~mm}$, mean stent length $25 \mathrm{~mm}$, mean fluoroscopic time of $19 \mathrm{~min}$, and $>80 \%$ of IVUS or OCT guidance. Coronary morphology is modified by stenting with a trend toward a more circular lumen (Figure 2). However, the latter remains generally ovoid after stenting of an intramural pathway. There were no periprocedural complications. Clinical follow-up at 6 months was uneventful in all but one patient requiring a new hospitalization at 5 months for persistent angina reported to be a vasospastic angina. Two patients had in-stent restenosis between 6 and 12 months postprocedure needing a new PCI. No stent distortion was observed on follow-up CCTA (Figure 2). 


\section{LIMITATIONS AND STRENGTHS OF PCI}

As the surgery, we don't know the long-term outcomes of the management of AAOCA with PCI (Table 1). The strengths of the latter in comparison with the surgery are those usually observed in the CAD treatment, with a shorter hospital stay and less post procedural adverse events with the percutaneous approach. In addition, the latter may be accomplished by the vast majority of interventional cardiologists. In opposite, few cardiac surgeons are able to repair AAOCA.

\section{DISCUSSION}

R-AAOCA constitutes a major part of congenital coronary anomalies possibly responsible for ischemic symptoms or myocardial ischemia. The management of patients with $\mathrm{R}$ AAOCA remains controversial in the adult population. Current guidelines recommend a surgical repair for R-AAOCA with evidence of ischemia. A very low risk of SCD, the lack of randomized controlled studies and scarcity of long-term data may explain the low rate of surgically treated patients. A percutaneous approach may provide an interesting alternative in a selected adult population. Our experience and that of others showed that stenting of an interarterial course was feasible and safe without risks of aortic or coronary dissection. Arterial remodeling associated with a significant increase in lumen area can explain symptom relief and myocardial ischemia resolution.

\section{REFERENCES}

1. Cheezum MK, Ghoshhajra B, Bittencourt MS, Hulten EA, Bhatt A, Mousavi $\mathrm{N}$, et al. Anomalous origin of the coronary artery arising from the opposite sinus: prevalence and outcomes in patients undergoing coronary CTA. Eur Heart J Cardiovasc Imaging. (2017) 18:224-35. doi: 10.1093/ehjci/jev323

2. Pérez-Pomares JM, de la Pompa JL, Franco D, Henderson D, Ho SY, Houyel L, et al. Congenital coronary arteries anomalies: a bridge from embryology to anatomy and pathophysiology-a position statement of the development, anatomy and pathology ESC Working Group. Cardiovasc Res. (2016) 109:204-16. doi: 10.1093/cvr/cvv251

3. Hoffman JI. Abnormal origins of the coronary arteries from the aortic root. Cardiol Young. (2014) 24:774-91. doi: 10.1017/S1047951114000250

4. Aubry P, Halna du Fretay X, Calvert PA, Dupouy P, Hayfil F, Laissy JP, et al. Proximal anomalous connections of coronary arteries in adults. In: Rao PS, editor. Congenital Heart Disease: Selected Aspects. Intech (2012). p. 181-230.

5. Brothers JA, Frommelt MA, Jaquiss RBD, Myerburg RJ, Fraser CD, Tweddell JS. Expert consensus guidelines: anomalous aortic origin of a coronary artery. J Thorac Cardiovasc Surg. (2017) 153:1440-57. doi: 10.1016/j.jtcvs.2016. 06.066

6. Stout KK, Daniels CJ, Aboulhosn JA, Bozkurt B, Broberg CS, Colman JM, et al. $2018 \mathrm{AHA} / \mathrm{ACC}$ guideline for the management of adults with congenital heart disease: a report of the American college of cardiology/American heart association task force on clinical practice guidelines. J Am Coll Cardiol. (2019) 73:1494-563. doi: 10.1161/CIR.0000000000000602

7. Penalver JM, Mosac RS, Weitz W, Phoon CKL. Anomalous aortic origin of coronary arteries from the opposite sinus: a critical appraisal of risk. $B M C$ Cardiovasc Disord. (2012) 12:83:1-10. doi: 10.1186/1471-2261-12-83

8. Mery CM. Decision making in anomalous aortic origin of a coronary artery. Congenit Heart Dis. (2017) 12:630-2. doi: 10.1111/chd.12493

9. Cheitlin MD, De Castro CM, McAllister HA. Sudden death as a complication of anomalous left coronary origin from the anterior sinus of
The design of the abovementioned studies did not allow the evaluation of the impact of stenting on SCD risks. We should consider the risk of in-stent restenosis (about 10\% of cases) that can be difficult to treat in case of strut protruding into the aorta. An extrinsic compression of a metallic stent placed between the great vessels has not been reported yet. More information is needed with longitudinal studies of a larger population, longer clinical and CCTA follow-ups, and prospective data collection. In the future, a percutaneous option for the treatment of selected RAAOCA should be considered in the decision-making algorithm in specialized centers.

\section{AUTHOR CONTRIBUTIONS}

PA wrote the initial draft of the review and supervised corrections. PD contributed substantially to the content of the review. XHF and OB reviewed all drafts, providing revisions. All authors agree to be accountable for the content of the work.

\section{ANOCOR WORKING GROUP}

Dr. Pierre Aubry, Dr. Paul Barragan, Dr. Olivier Boudvillain, Dr. Philippe Commeau, Dr. Philippe Degrell, Dr. Patrick Dupouy, Reza Farnoud, Dr. Xavier Halna du Fretay, Dr, Fabien Hyafil, Dr. Jean-Michel Juliard, Prof. Jean-Pierre Laissy, Dr. Damien Millischer, Prof. Pascal Motreff, Dr. Mohammed Nejjari, Prof. Phalla Ou. valsalva. A not-so-minor congenital anomaly. Circulation. (1974) 50:780-7. doi: 10.1161/01.CIR.50.4.780

10. Kragel AH, Roberts WC. Anomalous origin of either the right or left main coronary artery from the aorta with subsequent coursing between aorta and pulmonary trunk: analysis of 32 necropsy cases. Am J Cardiol. (1988) 62:771-7. doi: 10.1016/0002-9149(88)91220-9

11. Frescura C, Basso C, Thiene G, Corrado D, Pennelli T, Angelini A, et al. Anomalous origin of coronary arteries and risk of sudden death: a study based on an autopsy population of congenital heart disease. Hum Pathol. (1998) 29:689-95. doi: 10.1016/S0046-8177(98)90277-5

12. Virmani R, Burke A, Farb A. Sudden cardiac death. Cardiovasc Pathol. (2001) 10:211-8. doi: 10.1016/S1054-8807(01)00091-6

13. Maron BJ, Doerer JJ, Haas TS, Tierney DM, Mueller FO. Sudden deaths in young competitive athletes: analysis of 1866 deaths in the United States, 1980-2006. Circulation. (2009) 119:1085-92. doi: 10.1161/CIRCULATIONAHA.108.804617

14. Harmon KG, Asif IM, Maleszewski JJ, Owens DS, Prutkin JM, Salerno JC, et al. Incidence, cause, and comparative frequency of sudden cardiac death in national collegiate athletic association athletes: a decade in review. Circulation. (2015) 132:10-9. doi: 10.1161/CIRCULATIONAHA.115. 015431

15. Aubry P, Halna du Fretay X, Degrell P, Waldmann V, Karam N, Marijon E. Sudden cardiac death and anomalous connections of the coronary arteries: what is known and what is unknown? Ann Cardiol Angeiol. (2017) 66:309-18. doi: 10.1016/j.ancard.2017.09.019

16. Finocchiaro G, Papadakis M, Robertus JL, Dhutia H, Steritis ALK, Tome M, et al. Etiology of sudden death in sports. Insights from a United regional registry. J Am Coll Cardiol. (2016) 67:2108-15.

17. Moustafa SE, Zehr K, Mookadam M, Lorenz EC, Mookadam F. Anomalous interarterial left coronary artery: An evidence based systemic overview. Int J Cardiol. (2008) 126:13-20. doi: 10.1016/j.ijcard.2007. 04.086 
18. Cheezum MK, Liberthson RR, Shah NR, Villines TC, O'Gara PT, Lanszberg $\mathrm{MJ}$, et al. Anomalous aortic origin of a coronary artery from the inappropriate sinus of valsalva. J Am Coll Cardiol. (2017) 69:1592-608. doi: 10.1016/j.jacc.2017.01.031

19. Priori SG, Blomström-Lundqvist C, Mazzanti A, Blom N, Borggrefe M, Camm J, et al. 2015 ESC Guidelines for the management of patients with ventricular arrhythmias and the prevention of sudden cardiac death: the task force for the management of patients with ventricular arrhythmias and the prevention of sudden cardiac death of the european society of cardiology (ESC). Endorsed by: association for european paediatric and congenital cardiology (AEPC). Eur Heart J. (2015) 36:2793-867. doi: 10.1093/eurheartj/ehv316

20. Molossi S, Agrawal H, Mery CM, Krisnamurthy R, Masand P, Kristen Sexton Tejtel S, et al. Outcomes of anomalous aortic origin of a coronary artery following a prospective standardized approach. Cir Cardiovasc Interv. (2020) 13:e008445. doi: 10.1161/CIRCINTERVENTIONS.119.008445

21. Baumgartner H, De Backer J, Babu-Narayan SV, Budts W, Chessa M, Diller GP, et al. 2020 ESC guidelines for the management of adult congenital heart disease. Eur Heart J. (2020) 41:4153-4. doi: 10.1093/eurheartj/ehaa701

22. Ong CS, Cameron DE, Jacobs ML. Surgical management of anomalous coronary arteries. Ann Cardiothorac Surg. (2018) 7:604-10. doi: 10.21037/acs.2018.08.02

23. Mery CM, Lawrence SM, Krishnamurthy R, Kristen Sexton-Tejtel S, Carberry $\mathrm{KE}, \mathrm{McKenzie} \mathrm{ED}$, et al. Anomalous aortic origin of a coronary artery: toward a standardized approach. Semin Thoracic Surg. (2014) 26:110-22. doi: 10.1053/j.semtcvs.2014.08.001

24. Mainwaring RD, Reddy VM, Reinhartz O, Petrossian E, Punn R, Hanley FL. Surgical repair of anomalous aortic origin of a coronary artery. Eur J Cardiothorac. (2014) 46:20-6. doi: 10.1093/ejcts/ezt614

25. Padalino MA, Franchetti N, Hazekamp M, Sojak V, Carrel T, Frigolia A, et al. Surgery for anomalous aortic origin of coronary arteries: a multicenter study from the European congenital heart surgeons association. Eur J Cardiothorac Surg. (2019) 56:693-703. doi: 10.1093/ejcts/ezz080

26. Nees SN, Flyer JN, Chelliah A, Dayton JF, Touchette L, Kalfa D, et al. Patients with anomalous aortic origin of the coronary artery remain at risk after surgical repair. J Thorac Cardiovasc Surg. (2018) 155:2554-64. doi: 10.1016/j.jtcvs.2017.12.134

27. Houyel L, Planché C. Interarterial and intramural coronary trajectories: anatomical aspects and surgical implications. Arch Mal Coeur. (2008) 95:500-6.

28. Aubry P, Honton B, Leurent G, Halna du Fretay X, Dupouy P, Ou P, et al. Ectopic connection of the left coronary artery with the contralateral sinus with or without intramural pathway: How and why differentiating them? Ann Cardiol Angeiol. (2014) 63:410-6. doi: 10.1016/j.ancard.2014.09.032

29. Angelini P. Novel imaging of coronary arteries anomalies to assess their prevalence, the causes of clinical symptoms, and the risk of sudden cardiac death. Circ Cardiovasc Imaging. (2014) 7:747-54. doi: 10.1161/CIRCIMAGING.113.000278

30. Miller JA, Anavekar NS, El Yaman MM, Burkhart HM, Mille AJ, Julsrud PR. Computed tomographic angiography identification of intramural segments in anomalous coronary arteries with interarterial course. Int J Cardiovasc Imaging. (2012) 28:1525-32. doi: 10.1007/s10554-011-9936-9
31. Gräni C, Buechel RR, Kaufmann PA, Kwong RY. Multimodality imaging in individuals with anomalous coronary arteries. $J \mathrm{Am}$ Coll Cardiol Imag. (2017) 10:471-81. doi: 10.1016/j.jcmg.2017. 02.004

32. Driesen BW, Warmerdam EG, Sieswerda GTJ, Shoof PH, Meijboom FJ, Haas F, et al. Anomalous coronary artery originating from the opposite sinus of Valsalva (ACAOS), fractional flow reserve- and intravascular ultrasoundguided management in adult patients. Catheter Cardiovasc Interv. (2018) 92:68-75. doi: 10.1002/ccd.27578

33. Doorey AJ, Pasquale MJ, Lally JF, Mintz GS, Marshall E, Ramos DA. Sixmonth success of intracoronary stenting for anomalous coronary arteries associated with myocardial ischemia. Am J Cardiol. (2000) 86:580-2. doi: 10.1016/S0002-9149(00)01023-7

34. Hariharan R, Kacere RD, Angelini P. Can stent-angioplasty be a valid alternative to surgery when revascularization is indicated for anomalous origination of a coronary artery form the opposite sinus? Tex Heart Inst J. (2002) 29:308-13

35. Angelini P, Uribe C, Monge J, Tobis JM, Elayda MA, Willerson JT. Origin of the right coronary artery from the opposite sinus of valsalva in adults: characterization by intravascular ultrasonography at baseline and after stent angioplasty. Catheter Cardiovasc Interv. (2015) 86:199-208. doi: $10.1002 / \mathrm{ccd} .26069$

36. Darki A, Motiwala A, Bakhos L, Lewis BE, Lopez JJ, Steen LH Jr et al. Technical success and long-term outcomes after anomalous right coronary artery stenting with cardiac computed tomography angiography correlation. Catheter Cardiovasc Interv. (2019) 96:586-97. doi: 10.1002/ ccd. 28453

37. de Oliveira DM, Gomes V, Caramori P. Intravascular ultrasound and pharmacological stress test to evaluate the anomalous origin of the right coronary artery. J Invasive Cardiol. (2012) 24:E131-4.

38. Lee SE, Yu CW, Park KW, Suh JW, Cho YS, Youn TJ, et al. Physiological and clinical relevance of anomalous right coronary artery origination from left sinus of Valsalva in adults. Heart. (2016) 102:114-9. doi: 10.1136/heartjnl-2015-308488

39. Degrell P, Halna Du Fretay X, Dupouy P, Barragan P, Nejjari M, Dugauquier $\mathrm{C}$, et al. Anomalous connection of the right coronary artery with interarterial course: preliminary prospective experience of stenting in a selected adult population. J Am Coll Cardiol. (2017) 70 (Suppl. B):B139-40. doi: 10.1016/j.jacc.2017.09.430

Conflict of Interest: The authors declare that the research was conducted in the absence of any commercial or financial relationships that could be construed as a potential conflict of interest.

Copyright (C) 2021 Aubry, Halna du Fretay, Boudvillain, Degrell and the ANOCOR Working Group. This is an open-access article distributed under the terms of the Creative Commons Attribution License (CC BY). The use, distribution or reproduction in other forums is permitted, provided the original author(s) and the copyright owner(s) are credited and that the original publication in this journal is cited, in accordance with accepted academic practice. No use, distribution or reproduction is permitted which does not comply with these terms. 